\title{
Power, Safety, and Learning in Racially Diverse Groups
}

\author{
ERICA GABRIELLE FOLDY \\ New York University \\ PETER RIVARD \\ Suffolk University \\ TAMARA R. BUCKLEY \\ Hunter College, City University of New York
}

\begin{abstract}
We propose that power inequities drive dynamics in racially diverse teams, often leading to conflict, withdrawal, or assimilation-all of which can impede team learning. We suggest several elements to address these dynamics, including identity safety or the belief that one is safe despite one's racial identity; a perspective that values cultural identity as a resource for thinking about work; and a welcoming stance toward new information and differing opinions.
\end{abstract}

Although research reviews agree that racially and ethnically diverse groups have more negative outcomes than other kinds of groups (Jackson, Joshi, \& Erhardt, 2003; Mannix \& Neale, 2005; Williams \& O'Reilly, 1998), the reasons are unclear. Conflict has been proposed as an intervening mechanism, but racially diverse teams do not consistently experience more conflict than other teams (Jackson et al., 2003; Mannix \& Neale, 2005; Williams \& O'Reilly, 1998). At this point, research has not satisfactorily explained why racially diverse groups have worse outcomes.

We suggest an answer to this puzzle by arguing that group dynamics in racially and ethnically diverse teams are driven by power imbalances related to those forms of diversity. While power inequities can result in overt conflict, they can also result in more subterronean processes-without observable contention-that still impede group effectiveness. We suggest that a perspective informed by awareness of power is better able to explain both openly conflictual and more subtly discordant group dynamics, accounting for why such groups have worse outcomes even without open conflict. We then sug-

An earlier version of this paper was presented to the Organization Development \& Change Division of the Academy of Management, 2004. Many thanks to its anonymous reviewers as well as to colleagues who read earlier (and, in some cases, multiple) drafts: Amy Edmondson, Robin Ely, Vicky Parker, Sharon Rogolsky, David Thomas and the members of Fulton 214 (Danna Greenberg, Tammy MacLean, Jenny Rudolph, and Steve Taylor). gest factors that can counter these power imbalances, establish psychological safety, and thereby enhance learning in these teams. Simply put, we explore the question "What enables learning in racially and ethnically diverse groups?"

Our work is rooted in a perspective that understands power as central to race relations in organizations, drawing on the work of Alderfer (Alderfer, Alderfer, Tucker, \& Tucker, 1980; Alderfer \& Smith, 1982); Nkomo (1992; Nkomo \& Cox, 1996); Ragins (1997) and others. As Linnehan and Konrad state, "Some of the most difficult problems arising among diverse workforces occur because [identity] groups are unequal in power" (1999: 399). We argue that such problems will likely manifest themselves in racially diverse teams.

Starting with this foundational understanding of the role of power, we suggest that only by holding perspectives-and engaging in behaviors-that attend to power dynamics can group members establish the psychological safety (Edmondson, 1999) necessary for learning in racially diverse teams. We build a model that integrates insights from research in three areas: (1) identity threat (Davies, Spencer, \& Steele, 2005; Steele, Spencer, \& Aronson, 2002) and identity safety (Plaut, 2002; Purdie-Vaughns, 2004); (2) diverse teams (Chatman, Polzer, Barsade, \& Neale, 1998; Gibson \& Vermeulen, 2003; van Knippenberg, De Dreu \& Homan, 2004; Webber \& Donahue, 2001), and diversity perspectives (Ely \& Thomas, 2001); and (3) team learning (Argyris \& Schön, 1996; Cook \& 


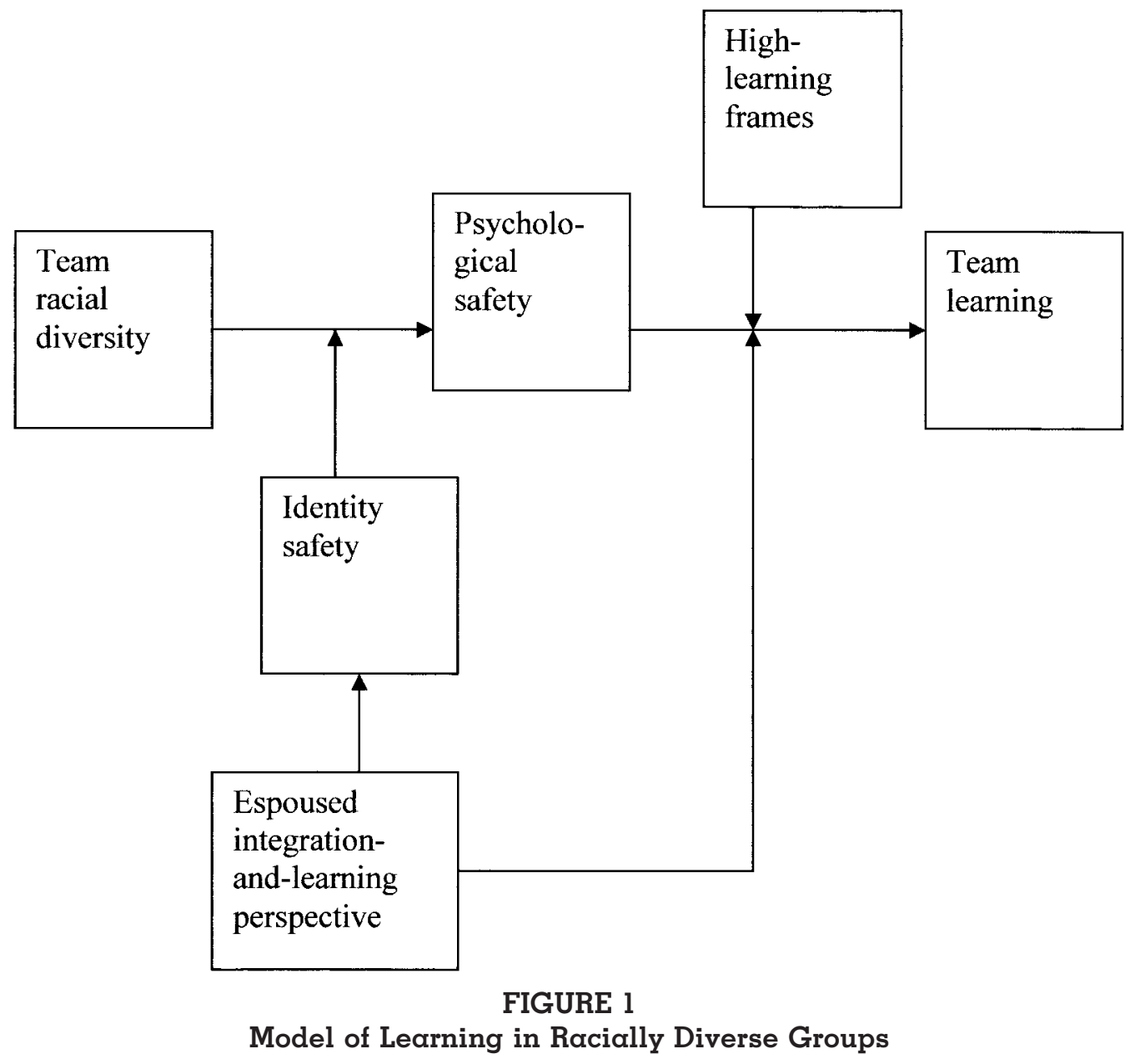

Seely Brown, 1999; Edmondson, 1999, 2002). We begin with a brief description of our model and then address each element and the relationships among them in greater depth. We end with the implications of our model for scholarship on team diversity and team learning, and for organizational practice and classroom teaching.

\section{A MODEL OF LEARNING IN RACIALLY DIVERSE GROUPS}

Figure 1 proposes a theoretical model of learning in racially and ethnically diverse groups. ${ }^{1}$

The backbone of the model is the relationship among team diversity, psychological safety, and team learning. Studies document that team learning is enabled by psychological safety, a teamlevel belief that there is mutual trust and respect

\footnotetext{
${ }^{1}$ While there are important distinctions between groups and teams, our argument is relevant for both; therefore, to avoid monotony, we use the terms interchangeably. Similarly, we use both "team learning" and "group learning" without making any distinction between them.
}

within the team (Edmondson, 1999; Edmondson, Bohmer, \& Pisano, 2001). Psychological safety encourages team learning behaviors, including such activities as experimenting, giving and receiving feedback, and raising errors or problems, by reducing fear that expressing different or challenging ideas will lead to sanction. However, little research has explicitly explored the relationship between team racial diversity and psychological safety. We argue that the simple relationship between team diversity and psychological safety, all else being equal, is likely to be negative (Ho, 2006).

However, we propose that this relationship can be moderated by the presence of identity safety (Davies et al., 2005), an individual's belief that his or her group identity-in this case racial identity-is welcome and does not incur risk in a group. We argue that the presence of identity safety will moderate the relationship between team diversity and psychological safety, making it more likely to be positive.

We argue further that identity safety is affected by the group's particular perspective on diversity (Ely \& Thomas, 2001). Ely and Thomas define diversity per- 
spective as a group's rationale for creating cultural diversity. It is a way of understanding cultural differences-including racial differences-and how they might be harnessed to further the group's work. Only one of the three perspectives identified by Ely and Thomas, the integration-and-learning perspective (ILP), enables culturally diverse groups to realize the potential of that diversity: It identifies cultural background as a rich resource for the group's thinking, turning potentially marginalized identities into welcome contributions. We suggest presence of the ILP will contribute to identity safety for group members who might otherwise feel identity threat. In addition, we also theorize that the ILP strengthens the already positive relationship between psychological safety and team learning. By identifying cultural background as a source of insight, the ILP encourages group members to surface ideas that they might otherwise have kept to themselves, thus potentially introducing new and different perspectives.

Finally, we suggest that high-learning fromes will further enhance the relationship between psychological safety and learning. Learning frames refer to a person's stance toward new information and new situations (Argyris, Putnam, \& Smith, 1985). Individuals can take a "protective," lowlearning approach, which seals them off from new ideas, or a "reflective," high-learning approach, which opens them to new understandings (Argyris et al., 1985: 283). We suggest these high-learning frames enable the group to engage with new ideas surfaced as a result of the ILP.

We now elaborate this model, beginning with its spine-the relationship among team racial diversity, psychological safety, and team learning. Then we discuss the three cognitive understandings-identity safety, the integration-and-learning perspective, and high-learning fromes-that, we argue, can enhance learning in culturally diverse teams. ${ }^{2}$

\footnotetext{
${ }^{2}$ We recognize that the model includes several different terms for cognitions: "beliefs" (in the case of psychological safety and identity safety), diversity "perspectives" and learning "frames." This is, in part, because we are following the originators' usage of each the constructs. In addition, the diversity perspective, as defined by Ely and Thomas, is a bundle of various beliefs, so the distinction there is only one of aggregation. However, there is a subtle difference between "beliefs" and "fromes." In this paper, we understand beliefs to be constructs that grow out of members' experiences within a particular team. Psychological safety, identity safety and diversity perspectives are all contextually derived. However, frames are portable individual-level concepts; an individual carries them to various situations and contexts. Certainly learning frames will be influenced by context as we discuss later, but they exist separately from any given team.
}

THE RELATIONSHIP AMONG TEAM RACIAL DIVERSITY, PSYCHOLOGICAL SAFETY, AND TEAM LEARNING

The backbone of the model is the relationship among team racial diversity, psychological safety, and team learning. To explore this relationship, we take each construct in turn, beginning with the outcome we are trying to explain, team learning.

\section{Team Learning}

Team learning consists of several interrelated dynamics: Individuals voicing ideas and enacting practices, making their tacit knowledge explicit; the group reflecting on and integrating these disparate ideas; and the group developing more generalizable understandings and routines that it applies to new areas (Argote, Gruenfeld, \& Naquin, 2001; Cook \& Seely Brown, 1999; Gherordi, 2000; Lave \& Wenger, 1991). Research in this area suggests that surfacing and engaging difference is at the heart of team learning. ${ }^{3}$

Yet, research shows that process can be inhibited by group interaction, even in homogeneous teams. Members are often concerned about others' evaluation of their contributions (Diehl \& Stroebe, 1987; Gallupe, Bastianutti, \& Cooper, 1991). Further, groups tend to focus on information they have in common, rather than members' unique perspectives (Stasser, 1999). Even if individuals surface conflicting views, team learning can be constrained by reluctance to engage those views, especially if they run counter to existing team knowledge and practice (Edmondson, 2002). Teams often develop shared routines that are difficult to break (Gersick \& Hackman, 1990; Levitt \& March, 1988). Many routines are defensive and habitual ways of protecting members from threat (Argyris, 1990; Argyris et al., 1985; Argyris \& Schön, 1996), especially threats to those with status and power (Berger, Ridgeway, Fisek, \& Norman, 1998; Contu \& Willmott, 2003; Lave \& Wenger, 1991). In such circumstances, even homogeneous groups engage in less productive and less creative problem solving (Falk \& Falk, 1981; Hoffman \& Maier, 1961; Nemeth, 1986)

\footnotetext{
${ }^{3}$ Researchers have defined learning as both a process (i.e., a set of behaviors) and an outcome (Edmondson, 1999: 353; Argote et al., 2001). We define learning as a process including behaviors such as experimenting, raising errors, and so forth. We are specifically interested in what enables these learning behaviors in racially diverse groups. Since ample research documents the importance of learning processes to the outcome of team effectiveness (e.g., Edmondson, 1999; Edmondson et al., 2001; Schilling, 2002; ZellmerBruhn, \& Gibson, 2006) we do not discuss that here.
} 
and less learning (Argote et al., 2001). But psychological safety seems to make a difference.

\section{Psychological Safety}

Psychological safety can counter the cognitive and interpersonal obstacles that stand in the way of surfacing and engaging different points of view. It is a "shared belief that the team is safe for interpersonal risk-taking" (Edmondson, 1999: 354). Examples of psychological safety beliefs include "It is safe to take a risk on this team" and "Members of this team are able to bring up problems and tough issues" (Edmondson, 1999: 382). Research suggests that psychological safety mediates the relationship between team structure and learning behaviors-without it, teams do not engage in the experimentation and reflection inherent to learning (Edmondson, 1999; Edmondson et al., 2001). Based on those studies, we suggest psychological safety will mediate the relationship between team racial diversity and team learning. We suggest further, based on research on culturally diverse teams, that the simple relationship between team diversity and psychological safety is likely to be negative (Ho, 2006). We explore this claim next.

\section{Racially Diverse Teams}

Although we explore learning in racially and ethnically diverse groups, empirical research in this specific area is slim (important contributions include Ely \& Thomas, 2001, and Gibson \& Vermeulen, 2003). Therefore, in addition to that material, we rely on the rich broader literature regarding racially and ethnically diverse teams. ${ }^{4}$

Although some studies suggest racial diversity can lead to team effectiveness (e.g., Cox, Lobel, \& McLeod, 1991; Sommers, 2006; Hong \& Page, 2004), several comprehensive reviews of the research literature conclude that racial diversity is, on balance, more likely to affect group outcomes negatively (Jackson et al., 2003: 810; Mannix \& Neale, 2005: 43; Willioms \& O’Reilly, 1998: 109, 113-114). However, the reasons remain unclear. A prevalent theory is that racial diversity increases the likeli-

\footnotetext{
${ }^{4}$ The line between race and ethnicity, never clear, has become increasingly obscure as both identities are broadly acknowledged to be socially constructed, rather than biologically based (Omi \& Winant, 1994). Some writers use "race" to refer to both terms; others consistently use both concepts. To avoid stylistic monotony, we have varied our terminology; when we use race alone it should be understood as including ethnicity as well. We also use the term "cultural diversity" to refer to racial and ethnic diversity.
}

hood of conflict, especially destructive emotional or relationship conflict, rather than the more constructive task conflict. While this seems plausible, research reviews point out that findings are mixed (Jackson et al., 2003: 809; Mannix \& Neale, 2005: 43; Williams \& O'Reilly, 1998: 110-111). For example, Pelled, Eisenhardt, and Xin (1999) did find that racial diversity was associated with higher levels of emotional conflict. However, other studies found no such relationship (O'Reilly, Williams, \& Barsade, 1997; Pelled, 1996). It seems possible that while racially diverse groups may not experience enough overt conflict to register on a questionnaire or during observation, more subtle forces work against the full engagement of group members and lead to poorer performance outcomes (cf. Pondy, 1967). We propose that such dynamics are in fact widespread in racially and ethnically diverse teams and that they are rooted in power imbalances among members. Those power imbalances then lead to conditions that undermine the creation of psychological safety, suggesting that the relationship between team racial diversity and psychological safety will tend to be negative.

\section{Power Imbalances and Their Effect on Psychological Safety}

The power perspective within the diversity literature has a long tradition. Embedded intergroup theory argued that societal differences in power, status, and resources are reflected in organizational processes, group dynamics, and interpersonal interactions, privileging whites at the expense of employees of color (Alderfer et al., 1980; Alderfer \& Smith, 1982). This has been echoed by many others (e.g., Linnehan \& Konrad, 1999; Nkomo, 1992; Prasad \& Mills, 1997; Ragins, 1997; Ridgeway \& Berger, 1986; Thomas, 1989). However, this perspective has largely been absent from the empirical research on racially diverse teams (see, e.g., Chatman et al., 1998; Gibson \& Vermeulen, 2003; Harrison, Price, \& Bell, 1998; Jehn, Northcraft, \& Neale, 1999; Pelled et al., 1999; Riordan \& Shore, 1997). Here we summarize the larger argument about race and power and apply it to culturally diverse teams.

Racial group membership in the United States is associated with differential access to resources and symbolic status, with whites relatively advantaged with respect to education, employment, and other social and economic indicators (Omi \& Winant, 1994; Loury, 2002; Massey \& Denton, 1993; McCall, 2001; Oliver \& Shapiro, 1997). Organizations import these imbalances: First, they often align their norms, values, and behaviors with the 
dominant group-most often European-American-creating monocultural environments (Cox, 1994; Fine, 1995; Prasad \& Mills, 1997) to which members of less powerful groups, most often those of color, must adapt. Second, this monoculturalism is structured into institutional practices, such as performance management systems (Sue \& Sue, 2003), which are "systematically hostile to the cultural values and lifestyles of different groups" (Prasad \& Mills, 1997: 16). Employees of color may not only feel less comfortable, they may be less likely to succeed, in part because institutional practices are biased against them. Ample research documents poorer work outcomes for employees of color compared to white employees (Cancio, Evans, \& Maume, 1996; Cornwell \& Kellough, 1994; Dreher \& Cox, 2000; Seidel, Polzer, \& Stewart, 2000).

These cultural and institutional practices not only reproduce societal inequities at the organizational level, they are incorporated into workgroups, re-creating power imbalances at the group level as well (McGrath, Berdahl, \& Arrow, 1995). These inequities disadvantage team members of color in several ways. First, white members are more likely than members of color to have workstyles that are in sync with organizational norms, thus giving white members the power to dictate, implicitly or explicitly, group interaction styles (Elsass \& Graves, 1997; Larkey, 1996; Ridgeway, 1997; Smith-Lovin \& Brody, 1989; Sue \& Sue, 2003). Members of color, with less power, face the burden of aligning with an external code of conduct that differs from their internal sense of self (Bell, 1990; Jones \& Shorter-Gooden, 2003; McGrath et al., 1995; Yoshino, 2006). Second, people of color may be targets of stereotyping (Brief, 1998, ch. 5; Cox, 1994; Steele, 1997). Stereotyping can be ubiquitous, automatic, and unconscious, a particular burden for people of color, who are more likely to be stereotyped negatively (Banaji, Hardin, \& Rothman, 1993; Banaji, Lemm, \& Carpenter, 2001; Greenwald \& Banaji, 1995).

For these reasons, team members of color may suffer "identity threat" (Morkus, Steele, \& Steele, 2000; Plaut, 2002; Steele et al., 2002). Identity threat is a "sense of threat to group identity arising from multiple sources tied to a long history of racial and group discrimination ..." (Markus et al., 2000: 238). Identity threat occurs in environments that, implicitly or explicitly, reproduce structures and patterns that give members of one group more power than those of other groups. An individual experiencing identity threat believes he could be "devalued, marginalized or discriminated against" (Steele et al., 2002: 417) because of his race. Therefore, other individual differences and group dynamics being equal, people of color are more likely to feel insecure specifically because of their racial or ethnic identity.

Given this threat, we suggest that team members of color are left with undesirable options. One is to resist the dominance of others and try to create space for their own ways and ideas. This approach is likely to result in overt conflict, especially relationship or process conflict (Jehn, 1995). However, as we noted earlier, racially diverse groups do not tend to experience higher levels of conflict. This suggests that team members of color may choose two other options. They could withdraw from the group, physically or psychologically, since being confronted with identity threat can decrease their commitment to their team (Purdie-Vaughns, Steele, Davies, \& Diltmann, 2008). Targets of stereotyping or discrimination frequently turn inward or toward their own group members as a result (Jetten, Branscombe, Schmitt, \& Spears, 2001; Konrad, 2003). A final alternative is to continue participating while trying to fit in. Assimilation is a common response to powerful pressures to conform (Fine, 1995; Kochman, 1989; McGrath et al., 1995; Sue \& Sue, 2003).

All these responses-resistance, withdrawal and assimilation-could potentially affect $a$ group's psychological safety. The conflict that arises from open resistance will reduce all members' trust and comfort in the team. The withdrawal of some team members indicates their own lack of safety and may spur resentment over inequitable burden sharing, which also undermines the mutuality necessary for psychological safety. While assimilation may provide some sense of comfort for white members, it can require members of color to behave in ways that feel inauthentic and contrived, which will undermine their sense of safety.

In sum, we suggest that the power imbalances associated with team racial diversity will trigger identity threat and therefore inhibit the team's sense of psychological safety. This could then extinguish the possibility of learning together, given the established link between psychological safety and learning. However these dynamics are not inevitable. The next several sections suggest critical team member cognitions that can help establish psychological safety and lead to team learning.

\section{IDENTITY SAFETY}

For psychological safety to be present, virtually all team members must feel safe (Edmondson, 1999). In diverse teams, we suggest that identity safety is a necessary precursor to psychological safety. Identity safety is an individual's belief that she "can 
function in [a given] setting without fear that [her] social identity will evoke devaluation and interference" (Steele et al., 2002: 425). An identity-safe environment assures "individuals that they are welcomed, supported and valued whatever their background" (Davies et al., 2005: 278). For our purposes, this means that a team not only gives a broad welcome to all members-which supports a general sense of psychological safety-but also that the team welcomes each member's particular racial or ethnic identity. In this way, "the crossgroup trust necessary for inclusion to occur can be built" (Plaut, 2002: 384). In other words, only in this way can a racially mixed group establish psychological safety. Identity safety is the individual sense of security that comes from knowing one's racial group is welcome that allows the team-level belief that a group is truly psychologically safe for risk taking more broadly. For that reason, we hypothesize that identity safety will moderate the relationship between team racial diversity and psychological safety, making it more likely to be positive.

This begs the important question of what preconditions prompt identity safety. It also raises another, related one: Although psychological safety is a prerequisite for learning in homogeneous groups (Edmondson, 1999), is it enough for racially diverse groups? We argue that two additional cognitive understandings are necessary to complete the model of learning in racially diverse teams. The integration-and-learning perspective, necessary to establishing identity safety, will also strengthen the relationship between psychological safety and learning behaviors. In addition, members' high-learning frames will further enhance the relationship between psychological safety and learning. We discuss each in turn.

\section{THE INTEGRATION-AND-LEARNING PERSPECTIVE}

Ely and Thomas $(2001,2003)$ have proposed that "diversity perspectives" moderate the relationship between cultural diversity and effective performance. Diversity perspectives are a workgrouplevel phenomenon; different workgroups within the same organization can hold different perspectives. A diversity perspective includes a group's justification for being diverse and its beliefs about the relevance of cultural diversity for thinking about work.

Ely and Thomas have identified three diversity perspectives. The discrimination-and-fairness perspective is most similar to a traditional affirmative action approach. From this perspective, the purpose of increasing the group's diversity is to redress past discrimination, not to enhance the group's work. Group members don't see racial or ethnic background as a source of experience or insight that could be useful for rethinking work processes, and they expect all employees to adopt standard practices and norms. The access-and-legitimacy perspective does attend to cultural differences, but superficially. Groups with this perspective tend to pigeonhole employees into roles that draw on their cultural expertise. For example, a social service agency might hire Vietnamese workers to work with immigrants from that country. This may enhance work processes, but the potential of such employees to generate new thinking about the broader work of the organization goes untapped.

The integration-and-learning perspective (ILP) argues that our varied cultural backgrounds offer fertile material for thinking about how we organize and carry out the breadth and depth of the work we do together. Members of groups with this perspective are more likely to think about how their own and others' cultural backgrounds can inform the group's work. In our model, the ILP plays two roles. First, it has an indirect effect, enabling identity safety for individual team members and thereby making it possible for the team to experience psychological safety. Second, it has a moderating effect, strengthening the relationship between psychological safety and team learning.

\section{Enabling Identity Safety}

The ILP contributes to identity safety by viewing varied racial and ethnic identities as assets that can broadly contribute to work and, therefore, as welcome additions. The ILP's explicit recognition of the value of cultural identity stands in contrast to the other two diversity perspectives, both of which entail aspects of color-blindness. While the other perspectives do motivate recruitment and retention of people of color, an assimilationist ethic dominates, although each perspective manifests it differently. The discrimination-and-fairness perspective understands race and ethnicity as primarily superficial and distracting differences, rather than as foundational identities that shape life experiences in ways relevant to the workplace. The access-and-legitimacy perspective acknowledges the importance of cultural background but only when working with members of the same identity group. While this perspective is not fully assimilationist, it is predominantly so, because minority group members must still assimilate to dominant ways of working, except when working with members of their own community. 
Although color-blindness was a step forward in 1950s America, today it has limitations for heterogeneous groups attempting to learn collectively. Team-learning research has found that the learning process involves making differences explicit in order to understand them, yet color-blindness works against this by suggesting that cultural differences are either superficial or threatening. "When operating under a color-blind set of assumptions, social categories are viewed as negative information to be avoided ..." (Wolsko, Park, Judd, \& Wittenbrink, 2000: 649). If the very act of paying attention to race is risky, then members of racial minorities-who trigger that attentionare tainted by the association. Therefore, colorblind approaches do not ease identity threat, while "value-in-diversity" approaches do (Plaut, 2002; Purdie-Vaughns et al., 2008; Steele et al., 2002). Safety is enhanced by an approach, such as the ILP, that acknowledges differences. The ILP is quite explicitly not color-blind: It not only acknowledges that our group identities say a great deal about who we are, it anticipates that those identities can offer sustenance for the team as a whole.

The ILP's explicit welcome of diverse cultural identities is an important step toward establishing identity safety, but a simple "valuing diversity" message alone would not sufficiently address the power dynamics that underlie intergroup relations. Therefore, another contribution of the ILP is its implicit acknowledgment that learning from difference cannot happen without addressing the power asymmetries that inhibit participation and communication.

To understand this contribution, it is helpful to take a closer look at color-blindness. The seemingly neutral stance of color-blindness can in fact serve to rationalize the status quo and its existing power relations (Omi \& Winant, 1994). Frankenberg, a sociologist of race, refuses to use the term "color-blindness," renaming it "color evasiveness" or "power evasiveness" (1993: 14). She argues that color-blindness hides, rather than precludes, attention to color, leaving in place current patterns of discrimination. In addition, color-blindness is an espoused theory that is almost impossible to enact (Omi \& Winant, 1994), a position supported by the extensive research on implicit and unconscious stereotypes (Banaji et al., 1993, 2001; Greenwald \& Banaji, 1995). Frankenberg argues that only "racecognizance," a clear attention to difference and to power, has the potential to challenge the status quo (1993: 15).

Frankenberg's work suggests that organizations with a color-blind stance are supporting current discriminatory arrangements, which include sta- tus hierarchies and cultural norms imported from the broader society (Ely \& Meyerson, 2000). Among the diversity perspectives, it is only the "colorcognizant" ILP that challenges, on this fundamental level, how organizations think about their work. As we noted earlier, members of marginalized groups typically must adapt to the culture and norms of the dominant group, which is one way in which power differentials among identity groups exact a toll (Bell, 1990; Konrad, 2003; Markus et al., 2000; McGrath et al., 1995; Yoshino, 2006). The ILP requires that white members adapt as well by learning from and with members of color about how to understand race and ethnicity and its impact on work. An approach very similar to the ILP is described by one scholar as "a power-sharing model that calls for the expectation of change" (Plaut, 2002: 384). This power-sharing approach helps to establish identity safety and, therefore, psychological safety.

\section{Strengthening the Relationship Between Psychological Safety and Team Learning}

In addition to its indirect influence on psychological safety by way of identity safety, we argue that the ILP also has a moderating influence on team learning, by strengthening the relationship between psychological safety and learning behaviors. The very aspect of the ILP that leads to identity safety-its legitimating of cultural background as a source of new ideas-also encourages group members to surface ideas that they might otherwise have kept to themselves, thus potentially introducing new and different perspectives. For groups engaged in complex, nonroutine tasks, these new perspectives add value and increase the possibility of team learning.

However, the rationale of the ILP is easier to state as an espoused intention than to implement in practice, since group members are more likely to view differences as threatening. Work from the learning literature suggests how to turn this intention into practice.

\section{HIGH-LEARNING FRAMES}

In their review of the organizational learning literature, Edmondson and Moingeon identify "properties of individual cognition as the critical source of leverage for creating more effective organizations" (1998: 16). One stream of work exploring the notion of "learning frames" comes from the work of Argyris and colleagues (Argyris \& Schön,1974, 1996; Argyris, Putnam, \& Smith, 1985). Learning frames re- 
TABLE 1

\section{Generic High-Learning and Low-Learning Frames}

High-Learning Frames
Low-Learning Frames
1. Mistakes are puzzles to be engaged.

2. Other people may have information or understanding that I lack.

3. I can learn from others.

4. It is helpful to raise problems, even if I don't have a solution.

5. Just because I feel uncomfortable in this discussion doesn't mean I shouldn't stick with it.

6. I have something to say and should contribute, even though I may be criticized.

7. I can make a contribution here even though I don't have any formal power or authority.
1. Mistakes are crimes to be prosecuted.
2. I have a complete picture of this situation.
3. I don't have anything to learn from others in this group.
4. If I don't have a solution, I shouldn't raise the problem.
5. If I feel uncomfortable in this discussion, something must be wrong.
6. Speaking up invites criticism.
7. I'm powerless in this group, so I will be quiet.

Note. From "Learning from Diversity: A Theoretical Exploration," by E. G. Foldy, 2004, Public Administration Review, 64(5): 529-538. Copyright 2004 by John Wiley and Sons, Ltd. Adapted by permission.

See also Argyris et al., 1985: 280.

fer to a person's stance toward new information. They are illustrated by an individual's approach to a viewpoint that differs from his own (is this intriguing or annoying?) and thereby influence whether team members can truly engage and integrate a range of perspectives. Low-learning frames (also called "protective" [Argyris et al., 1985] or Model I [Argyris \& Schön, 1996] fromes) motivate avoidance of criticism and a disinterest in new information. They could include "Speaking up invites criticism" and "I have a complete picture of this situation." In contrast, high-learning fromes (also called "reflective" or Model II frames) show an interest in contributing to discussion and curiosity about others' views. They could include "I have something to say and should contribute, even though I may be criticized," and "Other people may have information or understanding that I lack." High-learning frames encourage team members to advocate for their own point of view and inquire into others' perceptions, a powerful combination. (See Table 1 for other examples of learning frames.)

Although Argyris and Schön have applied these concepts to organizations (1996), the preponderance of work has explored learning fromes as an individual-level construct that affects a person's capacity to learn in a given situation (Edmondson \& Moingeon, 1998). Individuals tend toward either high- or low-learning frames and are likely to carry these tendencies to their various life situations (Kegan, 1994; Senge, 1990; Torbert, 1987), but these frames are also subject to influence from the social and organizational context (Schön, 1983). For example, a psychologically safe team may draw out or make salient high-learning frames, since admitting vulnerability and taking risks are perceived as safe, or a racially diverse team may trigger low-learning frames if members feel threatened and believe they need to protect themselves. Therefore, were we to broaden the discussion on our model, we would include a feedback loop between the environment and applied learning frames. However, the core of our model is consistent with previous research maintaining that there is an individual-level tendency toward certain learning fromes that is likely to manifest itself across many environments, rather than being entirely context-dependent.

As with the ILP, high-learning fromes will strengthen the relationship between psychological safety and learning behaviors in culturally diverse groups; however, we suggest they contribute in a different way. Simply stated, learning frames transform the espoused rationale of the ILP to an enacted theory-in-use (Argyris \& Schön, 1996). The ILP encourages the surfacing of views deriving from cultural background, while learning frames facilitate the engagement and integration of these different ideas. They provide group members with the capacity to confront difference productively and constructively. They do so in two ways.

First, they legitimize the risky step of raising "undiscussables," including those growing out of power asymmetries. Cultural differences such as race and ethnicity are often taboo topics in organizational life (Frankenberg, 1993: 6; Tatum, 1992; Thomas, 1989). "Undiscussables"-issues that threaten shame or embarrassment-impede learning in groups: They are seen as so dangerous that they cannot be raised without triggering defensive reactions among participants (Argyris et al., 1985: 86-87). Race is largely undiscussable in American life because it is so charged for whites and people of color alike, raising feelings of anger, privilege, guilt, and injustice. So, too, are the power inequi- 
ties inherent in most group dynamics, whether they are associated with status, hierarchy, or racial differences. High-learning fromes authorize the risk taking inherent in surfacing taboos. They go hand-in-hand with the belief that undiscussables impede authentic team affinity and productivity. If a team member believes it is helpful to raise problems without knowing the solution, or that one can make a contribution regardless of power in the group, she is more likely to speak up.

Second, they make it more likely that such a step will have positive consequences. The choice to speak up can trigger defensive reactions that in turn lead to discomfort and thorny misunderstandings (Murnighan \& Conlon, 1991; Von Glinow, Shapiro, \& Brett, 2004). But team members' high-learning frames are helpful here as well: Members believe they can learn from others; they see differences of opinion as something to actively debate and integrate. If members believe that their discomfort with risky topics signals a learning opportunity, they are more likely to tolerate it. Highlearning frames authorize reflection about one's own point of view and curiosity about others': In other words, they catalyze the learning in the integration-and-learning perspective.

In summary, we argue that both the ILP and generic high-learning fromes will moderate the relationship between psychological safety and learning behaviors. The espoused ILP helps establish a sense of trust and comfort for those who might feel their identities put them at risk, and it provides the rationale for surfacing differences. High-learning fromes help team members engage and integrate those differences. Together, they not only acknowledge cultural differences and their related power dynamics, they enhance the team's ability to address them.

\section{LEARNING BEHAVIORS IN RACIALLY DIVERSE GROUPS}

In the face of identity threat, as we argued earlier, team members of color are faced with several unsatisfactory options: resistance, withdrawal, or assimilation. However, teams with identity safety, the ILP, and high-learning frames have more constructive choices. Under these conditions, white members are less likely to dominate the group's functioning and more likely to value contributions different from their own. They will have a greater tendency to inquire about others' views, instead of only advocating for their own. This gives team members of color new options. Rather than feeling a need to resist the dominant approach and push for theirs, they are also more likely to advocate for their own views, while being curious about others'. This airing of differing perspectives is less likely to lead to destructive conflict. Members of color are more likely to engage in, rather than withdraw from, team processes, reducing white members' perception that they should control the group more firmly. And when members of color stay true to their own beliefs and behaviors, rather than assimilate, they provide richer material with which the group can work. Therefore, these groups are more likely to engage in the kind of questioning, risk taking, and experimentation that drives learning.

This reflection could encompass not only the general way in which work is carried out, but also include the particular domain of cultural difference and its impact on the work. Experimentation might include trying out several culturally influenced approaches. Seeking feedback might mean inquiring into the impact of a given approach on different racial or ethnic groups in the team's client population. Raising tough issues could involve a member asking the team to consider on incident in which he felt unheard or devalued due to race.

Groups like this will not be utopias. They will suffer their share of defensiveness, anger, and anxiety. They are not immune from the societal and organizational contexts in which they operate. Individual members, and the group as a whole, may feel ongoing pressure to align more closely with dominant patterns or subgroup allegiances. But unlike other groups, they are more likely to be aware of these pressures, to surface them, and to address them, rather than avoid them. There is some evidence, in fact, that such groups can trigger a virtuous cycle rather than a vicious one, experiencing synergies beyond those of homogeneous teams (Cox et al., 1991; Ely \& Thomas, 2003; Watson, Kumar, \& Michaelson, 1993). Jehn and colleagues noted this possibility in their discussion of a study which included gender and age diversity: "Being able to work together successfully, even when the group is diverse with respect to age and gender composition, may result in greater morale because the group has overcome a serious challenge to its effectiveness" (Jehn et al., 1999: 758). The same may be true of racially mixed teams.

\section{DISCUSSION AND IMPLICATIONS}

We make two primary contributions here. First, we propose an answer to a puzzle about racially diverse teams: Why do such teams have worse outcomes, although they do not necessarily have more conflict? We posit racially based power differentials as a driver of group dynamics and demon- 
strate how they can result in open conflict or in more subterranean dynamics of withdrawal or assimilation that can also be destructive. Therefore, research focusing on conflict as a primary intervening mechanism will, we believe, yield limited results. Placing power inequities as central to the teams' functioning suggests a more comprehensive understanding of the dynamics of these teams, explaining why they have worse outcomes even without increased conflict. ${ }^{5}$

Second, we integrate research from the stereotype threat, diversity, and team-learning literatures to suggest several elements that can address these power dynamics, thus potentially transforming the capacity of the group to learn together: identity safety, the integration-and-learning perspective, and high-learning frames. This represents a new approach.

In addition to these primary contributions, our work has implications for more specific areas of research on racially diverse teams and on team learning, as well as for classroom teaching and organizational practice. We address each in turn.

\section{Implications for Theory and Research on Racially Diverse Groups}

Our work encourages new thinking in two areas related to team diversity: the role of collectivist team norms and superordinate team identities, and the concept of diversity perspectives.

\section{Collectivist Team Norms and Superordinate Team Identities}

Recent research on team norms hypothesizes that outcomes in diverse teams are strengthened by cooperative, collectivist norms and cultures (Chatman \& Flynn, 2001; Chatman et al., 1998; Chatman \& Spataro, 2005; Jehn \& Bezrukova, 2004). Researchers argue that cooperative norms improve team outcomes by heightening the salience of superordinate team identities and interests and downplaying those of individuals (Chatman \& Flynn, 2001; Chatman et al., 1998). In one study, such norms eliminated the negative relationship between diversity and effectiveness, although they did not make it positive (Chatman \& Flynn, 2001).

\footnotetext{
${ }^{5}$ van Knippenberg, De Dreu, and Homan (2004) also argue that conflict is not central to team outcomes. They propose that "elaboration"-the extent to which group members surface relevant task information-is the key process. Conflict may help or hurt that process, but it is not the primary dynamic. This approach could dovetail well with ours in that power dynamics may inhibit elaboration for the reasons we have just described. This is intriguing and deserves further study.
}

Cooperative norms have beneficial effects on process outcomes such as satisfaction, conflict, and creativity (Chatmon \& Flynn, 2001; Chatmon et al., 1998). On the other hand, another study found that a collectivist culture had few and mixed significant effects on the relationship between diversity and performance (Jehn \& Bezrukova, 2004). Therefore, the impact of these norms is unclear.

An argument-sometimes implicit, sometimes explicit-behind cooperative norms and cultures is that they work because they make team identity more salient at the expense of demographic identities, like race (Bezrukova \& Jehn, 2002; Bezrukova, Jehn, \& Gounder, 2003; Chatman \& Flynn, 2001; Chatman et al., 1998). This logic is bolstered by positing a "functional antagonism" between identities, such that two different identities cannot both be highly salient at the same time (Chatman et al., 1998: 751). However, significant research suggests that it is possible to hold multiple strong identifications simultaneously (Hornsey \& Hogg, 2000; Huo, 2003; Huo, Smith, Tyler, \& Lind, 1996; Chattopadhyay, 2005).

Further, downplaying cultural identity in favor of team identity overlooks the implications such sublimation could have for those with less power and for the group's learning. Race and ethnicity are primary categories of difference that we use to understand and stratify our world, even from a young age (Jenkins, 1996: 21). As we argued earlier, approaches that try to ignore color often don't succeed. They can, paradoxically, signal that racial differences are problematic-particularly for those who are different from the norm. Consistent with this, recent research found that emphasizing a superordinate identity at the expense of subidentities actually increased intergroup bias, rather than decreasing it. In contrast, those who held both identities simultaneously had lower levels of bias (Hornsey \& Hogg, 2000).

In addition, downplaying racial difference often means overlooking characteristics that individuals cherish as central to who they are. Those different from the racial norm are more likely to be asked to suppress racial identity, exactly the kind of intervention that con trigger identity threat since it suggests that one's identity is unwelcome. Studies of interpersonal congruence-the extent to which group members are seen by others in the group as they see themselves-find that it leads to team effectiveness (Milton, 2005; Polzer, Milton, \& Swann, 2002; Swann, Polzer, Seyle, \& Ko, 2004). In fact, this research suggests that interpersonal congruence enhances the effect of diversity, including racial diversity, on performance.

Finally, learning grows out of difference. While 
some may argue that team members can leverage other kinds of differences without attending to cultural difference, research cited above suggests this is unlikely: If one's identity is unwelcome, then perhaps one's ideas are as well. Conversely, the very act of holding two potentially conflicting identities could in fact drive learning, as suggested by research showing that simultaneously holding conflicting notions can lead to change (Bartunek, 1984; Foldy, 2006; Mitroff \& Emshoff, 1979; Osland \& Bird, 2000).

For these reasons, the collectivist norms approach of downplaying a strong racial identity while playing up a superordinate identity overlooks-and may reinforce-power dynamics in the group, discouraging learning. Making nonshared identities salient, such as cultural identities, does risk triggering intergroup conflict, but it can also lead to group learning. We offer an approach whereby the group can replace intergroup competition with inquiry and dialogue, creating an environment in which a strong rooting in cultural identity gives members the security and curiosity to understand those with other identities.

\section{Diversity Perspectives}

Our model also enhances understanding of diversity perspectives. First, we posit two specific ways in which the ILP contributes to team learning: The ILP is an antecedent of identity safety, which then plays its own important role, and the ILP strengthens the relationship between psychological safety and team learning. Second, we elaborate the ILP by connecting it with the team-learning literature. In particular, we suggest that high-learning frames enable groups to realize the potential benefits of the integration-and-learning perspective. Previous work assumed that groups who hold the rationale for diversity stated in the ILP are also able to create the group processes which allow members to use identity as a source of skill and expertise (Ely \& Thomas, 2001). However, we argue that that is not necessarily the case and identify an element that allows the ILP to lead to team learning: high-learning frames. Without these frames, groups might appreciate the wisdom of diverse groups and might aspire to create a multicultural, rather than monocultural, environment. But without a learning approach they lack the capacity to realize those ideals.

\section{Implications for Theory and Research on Team Learning}

We suggest two ways in which we contribute to the work on team learning: by addressing power dy- namics and by suggesting antecedents to and moderators of psychological safety.

\section{Power}

While significant research on team learning has attended to organizational context (Levitt \& March, 1988; Nevis, DiBella, \& Gould, 1995; Popper \& Lipshitz, 1998), most has divorced learning from its broader social context (for exceptions see Contu \& Willmott, 2003; Lave \& Wenger, 1991). Investigating the impact of racial diversity contextualizes team learning to its societal environment. It suggests that teams and their learning processes will be affected by the society they inhabit-its history, social stratification, and culture. Few have applied this insight to team racial composition and its effect on team learning (exceptions include Ely \& Thomas, 2001, 2003, and Lorbiecki, 2001).

Attending to cultural difference also expands our understanding of how power dynamics affect learning. Some previous work explores the relationship between power and learning, including hierarchical power (Contu \& Willmott, 2003; Edmondson, 2002; Edmondson et al., 2003; Lave \& Wenger, 1991) and professional status (Nembhard \& Edmondson, 2006). However, most work on learning within cultural diversity has ignored power differentials based on group identity as a factor (Child \& Rodrigues, 2003; Gibson \& Vermeulen, 2003; Taylor \& Osland, 2003). We argue that racially mixed teams are likely to reflect power asymmetries of the larger environment. A team's reproduction of those power differentials then impedes the processes of surfacing and discussing different perspectives and points of view.

\section{Psychological Safety}

This work explores the effect of demographic composition on psychological safety. Previous work does not distinguish among the experiences of different team members based on their racial or ethnic identity. It presumes that team members are in structurally similar positions and are likely to share a sense of safety or lack of safety regardless of cultural identity. Therefore it doesn't consider the possibility that there might be a need for individual identity safety in order for a group to establish psychological safety. Color-blindness may be endorsed precisely as a way to make everyone feel safer, since it attempts to emphasize what members have in common which should lead to a greater sense of security (Apfelbaum, Sommers, \& Norton, 2008). However, our work here and others' elsewhere argue that precisely the opposite is true 
for those whose identity is different from the norm.

Edmondson also suggests a simple and direct relationship between psychological safety and learning (1999; Edmondson et al., 2001), while we suggest two moderators that could enhance that relationship, the ILP and high-learning frames, particularly for racially mixed groups. High-learning frames may be helpful in other groups as well, however, and further work could also explore the possibility of other moderators.

\section{Implications for Classroom Teaching and Organizational Practice}

While a class of students differs from a workgroup, there are also many similarities. We suggest racially diverse classrooms will feel less safe to students than homogeneous ones. In fact, the majority of research on identity threat has occurred in educational settings and indicates that identity threat is a significant concern for students of color (Steele et al., 2002). Like their work counterparts, in the face of identity threat, students of color may resist, withdraw, or assimilate-all of which could dampen psychological safety and learning, for themselves and others. So, we suggest that identity safety, the integration-and-learning perspective, and high-learning fromes will enhonce learning in racially diverse classrooms as in heterogeneous teams.

Given these similarities, we suggest that our model has common implications for practice in both workplace and classroom. In both cases, our model begs the question of how groups and individuals can establish these important preconditions. While this is grist for a much longer discussion, we see several pathways.

First, the role of leaders-whether professors or managers-is essential. Faculty members might reflect on their own diversity perspectives. Do they see race and ethnicity as germane to the topics about which they teach? Or is culture irrelevant-meaning that insights and differences based in cultural background would add nothing to the classroom conversation? Culture may seem more immediately apt to some management topics (e.g., human resource management) than to others (e.g., operations); however, we suggest that faculty remain open to learning how culture may be relevant, perhaps in ways they couldn't have imagined.

Similarly, if organization leaders use the ILP as a basic guide in thinking about the organization's strategy and human resource policies and work to align subunits with that approach, workgroups are more likely to follow (Thomas \& Ely, 1996). Even the team leader would likely have a disproportionate impact, given research on the importance of that role (Edmondson et al., 2001; Druskat \& Wheeler, 2003; Hackman \& Wageman, 2005). If the leader explicitly names the importance of culture and draws on cultural insights, team members are more likely to do the same.

Leaders also play a key role in facilitating a learning stance. While we theorize high-learning frames as an individual-level characteristic, they are certainly influenced by context (Schön, 1983). The more a faculty member models a learning stance, the more likely students will as well. This could mean a faculty member acknowledging that there may be times when students know more than he does; that he may lack the complete picture on a given topic; and that understanding errors rather than punishing them is more likely to lead to learning (and to apply this to himself as well as his students). As in the classroom, the modeling of high-learning frames by organizational leaders could be the most powerful catalyst for growth among its members. If a top leader takes a genuinely curious stance, we suggest that this will encourage more curiosity among her employeesand this will enhance the possibility of learning.

Second, while the modeling of leaders is critical, so is training and coaching. Diversity training in organizations and schools could be a vehicle for teaching the ILP. A workshop could describe the three diversity perspectives, discuss what the ILP adds, and ask participants to identify the perspective used by their workgroup. It could also encourage participants to think about their work and imagine ways in which cultural background could be a resource.

As for learning frames, there is a long history of educators and consultants working with students and employees to adopt a reflective or highlearning stance, rather than a protective or lowlearning one. This includes learning the metaskill of being able to reflect on and modify our embedded, automatic responses that block new ways of thinking and acting. This can involve individuals identifying their own problematic interactions and analyzing them to understand their contribution, as well as engaging in role-plays on how to give feedback to employees and other difficult conversations. While a more detailed description is outside the scope of this article, others have explored this at length (Kegan \& Lahey, 200l; Argyris et al., 1985; Torbert \& Associates, 2004; Friedman \& Lipshitz, 1992; Toylor, Rudolph, \& Foldy, 2007).

Finally, our approach does contradict the implications of another, increasingly popular approach: considering the role of faultlines in diverse teams. 
Faultlines are "hypothetical dividing lines that may split a group into subgroups based on one or more attributes" (Lau \& Murnighan, 1998: 328). Some researchers have found that moderate-tostrong subgroup strength led to better group outcomes (Gibson \& Vermeulen, 2003; Thatcher, Jehn, \& Zanutto, 2003; Lau \& Murnighan, 2005), although others have found that faultlines increase conflict and decrease effectiveness (Bezrukova \& Jehn, 2002; Li \& Hambrick, 2005). Despite the mixed findings, it is certainly worth investigating whether subgroups-the presence of others like themselves-can make members feel safer and more likely to surface conflicting ideas. This structural argument could usefully complement our focus on cognition.

However, one key implication of faultline research is that managers should attend to the possibility of subgroup activation when assembling teams, but in reality managers often have little control over the demographic make-up of their workgroups. Instead, our model suggests that diverse groups need to be equipped to manage that diversity in constructive ways. Further, some have suggested that managers should avoid charging groups that include potential faultlines with "demographically related" tasks that could activate the faultline (Lau \& Murnighan, 1998: 338). However, that means that the very issues where the group's diversity might be particularly relevant are taken out of the group's purview, quashing one of the specific justifications for diversity in the first place. Rather, we suggest research on how proactive modeling, training, and coaching, both on diversity perspectives and on learning approaches, could help all groups.

\section{Further Questions}

This model leaves several important questions unanswered. First, the role of racial identity could be explored more deeply. Different racial identities could have different effects: the porticular dynamics and stereotypes related to people of Asian descent, for example, are different from those related to people of African descent. (And, of course, each group holds further diversity in nationality, ethnicity, religion, and so on.) Also, members of the same racial identity group may have different levels of identity development (Cross, 1991; Helms, 1990), and those with earlier stages might find a colorblind approach safer. While Steele at al. (2002: 417) argue that individual characteristics, including level of identity development, are unlikely to play a significant role, this question certainly deserves more study.
Other work could explore whether our model would apply to other demographic identities, such as gender. Like racial differences, gender differences are related to power imbalances and they tend to lead to poorer team outcomes (Mannix \& Neale, 2003: 43; Williams \& O'Reilly, 1998: 108). However, racial and gender diversity often have somewhat different consequences in individual studies (see, e.g., Kochan et al., 2003; Chatman, Polzer, Barsade, \& Neale, 1998), suggesting that somewhat different dynamics may be at play.

In sum, racial differences are charged differences. This term comes from the notion of an electrical current, an apt metaphor: That current brings both energy and danger, depending on how it is handled. Similarly, racially mixed groups may face increased synergy and anxiety, engagement and defensiveness. We argue that groups whose dynamics address the adverse effects of power differences are more likely to create the safety that leads to team learning.

\section{REFERENCES}

Alderfer, C. P., Alderfer, C. J., Tucker, L., \& Tucker, R. 1980. Diagnosing race relations in management. Journal of Applied Behavioral Science, 16: 135-166.

Alderfer, C. P., \& Smith, K. K. 1982. Studying intergroup relations embedded in organizations. Administrative Science Quarterly, 27: 35-65.

Apfelbaum, E. P., Sommers, S. R., \& Norton, M. I. 2008. Seeing race and seeming racist? Evaluating strategic colorblindness in social interaction. Journal of Personality and Social Psychology, 95(4): 918-932.

Argote, L., Gruenfeld, D., \& Naquin, C. 2001. Group learning in organizations. In M. E. Turner (Ed.), Groups at work: Theory and research: 369-411. Mahwah, NJ: Erlbaum.

Argyris, C. 1990. Overcoming organizational defenses: Facilitating organizational learning. Needham, MA: Allyn \& Bacon.

Argyris, C., Putnam, R., \& Smith, D. M. 1985. Action science. San Francisco: Jossey-Bass.

Argyris, C., \& Schön, D. A. 1974. Theory in practice: Increasing professional effectiveness. San Francisco: Jossey-Bass.

Argyris, C., \& Schön, D. A. 1996. Organizational learning II: Theory, method and practice. Reading, MA: Addison-Wesley.

Banaji, M. R., Hardin, C., \& Rothman, A. J. 1993. Implicit stereotyping in person judgment. Journal of Personality and Social Psychology, 65: 272-281.

Banaji, M. R., Lemm, K. M., \& Carpenter, S. J. 2001. Automatic and implicit processes in social cognition. In A. Tesser, \& N. Schwartz (Eds.), Blackwell handbook of social psychology: Intraindividual processes: 134-158. Oxford: Blackwell.

Bartunek, J. M. 1984. Changing interpretive schemes and organizational restructuring: The example of a religious order. Administrative Science Quarterly, 29: 355-372.

Bell, E. L. 1990. The bicultural life experience of career-oriented black women. Journal of Organizational Behavior, 11: 459477. 
Berger, J., Ridgeway, C. L., Fisek, M. H., \& Norman, R. Z. 1998. The legitimation and delegitimation of power and prestige orders. American Sociological Review, 63(3): 379-405.

Bezrukova, K., \& Jehn, K. 2002. Examining ethnic faultlines in groups: A multimethod study of demographic alignment, leadership profiles, coalition formation, intersubgroup conflict and group outcomes. Paper presented at the International Association of Conflict Management, Salt Lake City, UT.

Bezrukova, K., Jehn, K. A., \& Gounder, M. 2003. Persistence and visibility of group faultines: A theoretical model of the effect of group culture and team identity on the group faultlines-organizational conflict link. Paper presented at the International Association of Conflict Management, Melbourne, Australia.

Brief, A. P. 1998. Attitudes in and around organizations. Thousand Oaks, CA: Sage.

Cancio, A. S., Evans, D. T., \& Maume, D. J., Jr. 1996. Reconsidering the declining significance of race: Racial differences in early career wages. American Sociological Review, 61(4): 541-556.

Chatman, J. A., \& Flynn, F. J. 2001. The influence of demographic heterogeneity on the emergence and consequences of cooperative norms in work teams. Academy of Management Journal, 44(5): 956-974.

Chatman, J. A., Polzer, J. T., Barsade, S. G., \& Neale, M. A. 1998. Being different yet feeling similar: The influence of demographic composition and organizational culture on work processes and outcomes. Administrative Science Quarterly, 43: 749-780.

Chatman, J. A., \& Spataro, S. 2005. Using self-categorization theory to understand relational demography-based variations in people's responsiveness to organizational culture. Academy of Management Journal, 48(2): 321-331.

Chattopadhyah, E.G. P. 2005. One foot in each camp: The dual identification of contract workers. Administrative Science Quarterly, 50: 68-99.

Child, J., \& Rodrigues, S. 2003. Social identity and organizational learning. In M. Easterby-Smith, \& M. A. Lyles (Eds.), Blackwell handbook of organizational learning and knowledge management: 535-556. Oxford, UK: Blackwell.

Contu, A., \& Willmott, H. 2003. Re-embedding situatedness: The importance of power relations in learning theory. Organization Science, 14(3): 283-296.

Cook, S. D. N., \& Seely Brown, J. 1999. Bridging epistemologies: The generative dance between organizational knowledge and organizational knowing. Organization Science, 10(4): 381-400.

Cornwell, C., \& Kellough, E. J. 1994. Women and minorities in federal government agencies: Examining new evidence from panel data. Public Administration Review, 54(3): 265270.

Cox, T., Jr. 1994. Cultural diversity in organizations: Theory, research and practice. San Francisco: Berrett-Koehler.

Cox, T., Lobel, S., \& McLeod, P. 1991. Effects of ethnic group cultural differences on cooperative and competititve behavior on a group task. Academy of Management Journal, 34(4): 827-847.

Cross, W. E., Jr. 1991. Shades of Black: Diversity in AfricanAmerican identity. Philadelphia: Temple University Press.
Davies, P. G., Spencer, S. J., \& Steele, C. M. 2005. Clearing the air: Identity safety moderates the effects of stereotype threat on women's leadership aspirations. Journal of Personality and Social Psychology, 88(2): 276-287.

Diehl, M., \& Stroebe, W. 1987. Productivity loss in brainstorming groups: Toward the solution of a riddle. Journal of Personality and Social Psychology, 53: 497-509.

Dreher, G. F., \& Cox, Jr., T. H. 2000. Labor market mobility and cash compensation: The moderating effects of race and gender. Academy of Management Journal, 43(5): 890-900.

Druskat, V. U., \& Wheeler, J. V. 2003. Managing from the boundary: The effective leadership of self-managing work teams. Academy of Management Journal, 46(4): 435-457.

Edmondson, A. C. 1999. Psychological safety and learning behavior in work teams. Administrative Science Quarterly, 44: 350-383.

Edmondson, A. C. 2002. The local and variegated nature of learning in organizations: A group-level perspective. Organization Science, 13(2): 128-146.

Edmondson, A. C. 2003. Framing for learning: Lessons in successful technology implementation. California Management Review, 45(2): 34-54.

Edmondson, A. C., Bohmer, R. M., \& Pisano, G. P. 2001. Disrupted routines: Team learning and new technology implementation in hospitals. Administrative Science Quarterly, 46: 685716.

Edmondson, A., \& Moingeon, B. 1998. From organizational learning to the learning organization. Management Learning, 29(1): 5-20.

Elsass, P. M., \& Graves, L. M. 1997. Demographic diversity in decision-making groups: The experiences of women and people of color. Academy of Management Review, 22(4): 946-973.

Ely, R. J., \& Meyerson, D. E. 2000. Theories of gender in organizations: A new approach to organizational analysis and change. Research in Organization Behavior: 105-153.

Ely, R. J., \& Thomas, D. A. 2001. Cultural diversity at work: The effects of diversity perspectives on work group processes and outcomes. Administrative Science Quarterly, 46(2): 229273.

Ely, R. J., \& Thomas, D. A. 2003. Team learning and the racial diversity-performance link. Working Paper. Boston, MA: Harvard Business School.

Falk, G., \& Falk, S. 1981. The impact of decision rules on the distribution of power in problem-solving teams with unequal power. Group \& Organization Studies, 6(2): 211-223.

Fine, M. G. 1995. Building successful multicultural organizations. Westport, CT: Quorum Books.

Foldy, E. G. 2006. Dueling schemata: Dialectical sensemaking about gender. Journal of Applied Behavioral Science, 42(3): 350-372.

Frankenberg, R. 1993. White women, race matters: The social construction of whiteness. Minneapolis: University of Minnesota Press.

Friedman, V., \& Lipshitz, R. 1992. Teaching people to shift cognitive gears: Overcoming resistance on the road to Model II. Journal of Applied Behavioral Science, 28(1): 118-136.

Gallupe, R. B., Bastianutti, L. M., \& Cooper, W. H. 1991. Unblocking brainstorms. Journal of Applied Psychology, 76(1): 137142 . 
Gersick, C. J. G., \& Hackman, J. R. 1990. Habitual routines in task-performing groups. Organizational Behavior and $\mathrm{Hu}$ man Decision Processes, 47: 65-97.

Gherardi, S. 2000. Practice-based theorizing on learning and knowing in organizations. Organization, 7(2): 211-223.

Gibson, C., \& Vermeulen, F. 2003. A healthy divide: Subgroups as a stimulus for team learning behavior. Administrative Science Quarterly, 48: 202-239.

Greenwald, A. G., \& Banaji, M. R. 1995. Implicit social cognition: Attitudes, self-esteem and stereotypes. Psychological Review, 102(1): 4-27.

Hackman, J. R., \& Wageman, R. 2005. A theory of team coaching. Academy of Management Review, 30(2): 269-287.

Harrison, D. A., Price, K. H., \& Bell, M. P. 1998. Beyond relational demography: Time and the effects of surface- and deeplevel diversity on work group cohesion. Academy of Management Journal, 41(1): 96-107.

Helms, J. E. 1990. Toward a model of white racial identity development. In J. E. Helms (Ed.), Black and White racial identity: Theory, research and practice: 49-66. New York: Greenwood Press.

Ho, C. 2006. Does heterogeneity inspire team psychological safety? Paper presented at the Academy of Management Annual Meetings, Atlanta, GA, August 14-16.

Hoffman, L. R., \& Maier, N. R. F. 1961. Quality and acceptance of problem solutions by members of homogeneous and heterogeneous groups. Journal of Abnormal and Social Psychology, 62(2): 401-407.

Hong, L., \& Page, S. E. 2004. Groups of diverse problem solvers can outperform groups of high-ability problem solvers. Proceedings of the National Academy of Sciences, 101(46): $16385-16389$.

Hornsey, M. J., \& Hogg, M. A. 2000. Subgoup relations: A comparison of mutual intergroup differentiation and common ingroup identity models of prejudice reduction. Personality and Social Psychology Bulletin, 26(2): 242-256.

Huo, Y. J. 2003. Procedural justice and social regulation across group boundaries: Does subgroup identity undermine relationship-based governance. Personality and Social Psychology Bulletin, 29(3): 336-348.

Huo, Y. J., Smith, H. J., Tyler, T. R., \& Lind, E. A. 1996. Superordinate identification, subgroup identification, and justice concerns. Psychological Science, 7(1): 40-45.

Jackson, S. E., Joshi, A., \& Erhardt, N. L. 2003. Recent research on team and organizational diversity: SWOT analysis and implications. Journal of Management, 6(29): 801-830.

Jehn, K. A. 1995. A multimethod examination of the benefits and detriments of intragroup conflict. Administrative Science Quarterly, 40: 256-282.

Jehn, K. A., \& Bezrukova, K. 2004. A field study of group diversity, workgroup context and performance. Journal of Organizational Behavior, 25: 703-729.

Jehn, K. A., Northcraft, G. B., \& Neale, M. A. 1999. Why differences make a difference: A field study of diversity, conflict and performance in workgroups. Administrative Science Quarterly, 44: 741-763.

Jenkins, R. 1996. Social identity. London: Routledge.

Jetten, J., Branscombe, N. R., Schmitt, M. T., \& Spears, R. 2001. Rebels with a cause: Group identification as a response to perceived discrimination from the mainstream. Personality and Social Psychology Bulletin, 27(9): 1204-1213.

Jones, C., \& Shorter-Gooden, K. 2003. Shifting: The double lives of Black women in America. HarperCollins.

Kegan, R. 1994. In over our heads: The mental demands of modern life. Cambridge, MA: Harvard University Press.

Kegan, R., \& Lahey, L. 2001. How the way we talk can change the way we work. San Francisco: Jossey-Bass.

Kochan, T., Bezrukova, K., Ely, R., Jackson, S., Joshi, A., Jehn, K., Leonard, J., Levine, D., \& Thomas, D. 2003. The effects of diversity on business performance: Report of the diversity research network. Human Resource Management, 42(1): 3-21.

Kochman, T. 1989. Black and white cultural styles in pluralistic perspective. In B. R. Gifford (Ed.), Test policy and test performance: Education, language and culture: 259-296. Norwell, MA: Kluwer Academic Publishers.

Konrad, A. M. 2003. Defining the domain of workplace diversity scholarship. Group \& Organization Management, 28(1): 4-17.

Larkey, L. K. 1996. Toward a theory of communicative interactions in culturally diverse workgroups. Academy of Management Review, 21: 463-491.

Lau, D. C., \& Murnighan, J. K. 1998. Demographic diversity and faultlines: The compositional dynamics of organizational groups. Academy of Management Review, 23(2): 325-340.

Lau, D. C., \& Murnighan, J. K. 2005. Interactions within groups and subgroups: The effects of demographic faultlines. Academy of Management Journal, 48(4): 645-659.

Lave, J., \& Wenger, E. 1991. Situated learning: Legitimate peripheral participation. Cambridge, England: Cambridge University Press.

Levitt, B., \& March, J. G. 1988. Organizational learning. Annual Review of Sociology, 14: 319-340.

Li, J., \& Hambrick, D. C. 2005. Factional groups: A new vantage on demographic faultlines, conflict, and disintegration in work teams. Academy of Management Journal, 48(5): 794813.

Linnehan, F., \& Konrad, A. M. 1999. Diluting diversity: Implications for intergroup inequality in organizations. Journal of Management Inquiry, 8(4): 399-414.

Lorbiecki, A. 2001. Changing views on diversity management: The rise of the learning perspective and the need to recognize social and political contradictions. Management Learning, 32(3): 345-361.

Loury, G. 2002. The anatomy of racial inequality. Cambridge, MA: Harvard University Press.

Mannix, E., \& Neale, M. A. 2005. What differences make a difference? The promise and reality of divesre teams in organizations. Psychological Science in the Public Interest, 6(2): 31-55.

Markus, H. R., Steele, C. M., \& Steele, D. M. 2000. Colorblindness as a barrier to inclusion: Assimilation and nonimmigrant minorities. Daedalus: Journal of the American Academy of Arts and Sciences, 129(4): 233-259.

Massey, D. S., \& Denton, N. A. 1993. American apartheid: Segregation and the making of the underclass. Cambridge, MA: Harvard University Press. 
McCall, L. 2001. Complex inequality: Gender, class and race in the new economy. New York: Routledge.

McGrath, J. E., Berdahl, J. L., \& Arrow, H. 1995. Traits, expectations, culture and clout: The dynamics of diversity in work groups. In S. E. Jackson, \& M. N. Ruderman (Eds.), Diversity in work teams: Research paradigms for a changing workplace: 17-45. Washington, DC: American Psychological Association.

Milton, L. P. 2005. Identity confirmation networks and cooperation in work groups. Academy of Management Journal, 48(2): 191-212.

Mitroff, I. I., \& Emshoff, J. R. 1979. On strategic assumption planning: A dialectical approach to policy and planning. Acadmy of Management Review, 4: 1-12.

Murnighan, J. K., \& Conlon, D. E. 1991. The dynamics of intense work groups: A study of British string quartets. Administrative Science Quarterly, 1991(36): 165-186.

Nembhard, I. M., \& Edmondson, A. C. 2006. Making it safe: The effects of leader inclusiveness and professional status on psychological safety and improvement efforts in health care teams. Working Paper, Boston, MA: Harvard Business School.

Nemeth, C. J. 1986. Differential contributions of majority and minority influence. Psychological Review, 93(1): 23-32.

Nevis, E. C., DiBella, A. J., \& Gould, J. M. 1995. Understanding organizations as learning systems. Sloan Management Review, 36(2): 73-86.

Nkomo, S. 1992. The emperor has no clothes: Rewriting "race in organizations." Academy of Management Review, 17(3): 487-513.

Nkomo, S. M., \& Cox, T., Jr. 1996. Diverse identities in organizations. In S. R. Clegg, C. Hardy, \& W. Nord (Eds.), Handbook of organization studies: 338-356. London: Sage.

O'Reilly, C. A., Williams, K., \& Barsade, S. 1997. Group demography and innovation: Does diversity help? In E. Mannix, \& M. A. Neale (Eds.), Research in the management of groups and teams, Vol. I. Greenwich, CT: JAI Press.

Oliver, M. L., \& Shapiro, T. M. 1997. Black wealth/White wealth: A new perspective on racial inequality. New York: Routledge.

Omi, M., \& Winant, H. 1994. Racial formation in the United States. New York: Routledge.

Osland, J. S., \& Bird, A. 2000. Beyond sophisticated stereotyping: Cultural sensemaking in context. Academy of Management Executive, 14(1): 65-79.

Pelled, L. H. 1996. Demographic diversity, conflict and work group outcomes: An intervening process theory. Organization Science, 7(6): 615-631.

Pelled, L. H., Eisenhardt, K. M., \& Xin, K. R. 1999. Exploring the black box: An analysis of work group diversity, conflict and performance. Administrative Science Quarterly, 44: 1-28.

Plaut, V. C. 2002. Cultural models of diversity in America: The psychology of difference and inclusion. In R. Schweder, M. Minow, \& H. R. Markus (Eds.), Engaging cultural differences: The multicultural challenge in liberal democracies: 365395. New York: Russell Sage Foundation.

Polzer, J. T., Milton, L. P., \& Swann, W. B. J. 2002. Capitalizing on diversity: Interpersonal congruence in small work groups. Administrative Science Quarterly, 47(2): 296-324.
Pondy, L. R. 1967. Organizational conflict: Concepts and models. Administrative Science Quarterly, 12(2): 296-320.

Popper, M., \& Lipshitz, R. 1998. Organizational learning mechanisms: A structural and cultural approach to organizational learning. Journal of Applied Behavioral Science, 34(2): 161179.

Prasad, P., \& Mills, A. 1997. From showcase to shadow: Understanding the dilemmas of managing workplace diversity. In P. Prasad, A. Mills, M. B. Elmes, \& A. Prasad (Eds.), Managing the organizational melting pot: Dilemmas of workplace diversity: 3-27. Thousand Oaks, CA: Sage.

Purdie-Vaughns, V. J. 2004. Identity contingency threat: The impact of circumstantial cues on African Americans' trust in diverse settings. Dissertation. Stanford University, Palo Alto, CA.

Purdie-Vaughns, V., Steele, C. M., Davies, P. G., Ditman, R., \& Crosby, J. R. 2008. Social identity contingencies: How diversity cues signal threat or safety for African Americans in mainstream institutions. Journal of Personality and Social Psychology, 94(4): 615-630.

Ragins, B. R. 1997. Diversified mentoring relationships in organizations: A power perspective. Academy of Management Review, 22: 482-521.

Ridgeway, C. L. 1997. Interaction and the conservation of gender inequality: Considering employment. American Sociological Review, 62(April): 218-235.

Ridgeway, C. L., \& Berger, J. 1986. Expectations, legitimation, and dominance behavior in task groups. American Sociological Review, 51: 603-617.

Riordan, C. M., \& Shore, L. M. 1997. Demographic diversity and employee attitudes: An empirical examination of relational demography within work units. Journal of Applied Psychology, 82(3): 342-358.

Schilling, M. A. 2002. Technology success and failure in winnertake-all markets: The impact of learning orientation, timing and network externalities. Academy of Management Journal, 45(2): 387-398.

Schön, D. A. 1983. Organizational learning. In G. Morgan (Ed.), Beyond method. Thousand Oaks: Sage.

Seidel, M.-D. L., Polzer, J. T., \& Stewart, K. J. 2000. Friends in high places: Networks on discrimination in salary negotiations. Administrative Science Quarterly, 45: 1-24.

Senge, P. M. 1990. The fifth discipline: The art and practice of the learning organization. New York: Doubleday.

Smith-Lovin, L., \& Brody, C. 1989. Interruptions in group discussions: The effects of gender and group composition. American Sociological Review, 54: 424-435.

Sommers, S. R. 2006. On racial diversity and group decisionmaking: Identifying multiple effects of racial composition on jury deliberations. Journal of Personality and Social Psychology, 90(4): 597-612.

Stasser, G. 1992. Information salience and the discovery of hidden profiles by decision-making groups: A "thought experiment." Organizational Behavior and Human Decision Processes, 52: 156-181.

Stasser, G. 1999. The uncertain role of unshared information in collective choice. In L. Thompson, J. Levine, \& D. Messick (Eds.), Shared knowledge in organizations. Hillsdale, NJ: Erlbaum

Steele, C. M. 1997. A threat in the air: How stereotypes shape 
intellectual identity and performance. American Psychologist, 52(6): 613-629.

Steele, C. M., Spencer, S. J., \& Aronson, J. 2002. Contending with group image: The psychology of stereotype and social identity threat. In M. P. Zanna (Ed.), Advances in experimental social psychology, Vol. 34: 379-440. San Diego, CA: Academic Press.

Sue, D. W., \& Sue, D. 2003. Counseling the culturally different: Theory and practice. New York: Wiley.

Swann, W. B., Jr., Polzer, J. T., Seyle, D. C., \& Ko, S. J. 2004. Finding value in diversity: Verification of personal and social selfviews in diverse groups. Academy of Management Review, 29(1): 9-27.

Tatum, B. D. 1992. Talking about race, learning about racism: The application of racial identity development theory in the classroom. Harvard Educational Review, 62(1): 1-24.

Taylor, S., \& Osland, J. S. 2003. The impact of intercultural communication on global organizational learning. In M. Easterby-Smith, \& M. A. Lyles (Eds.), Blackwell handbook of organizational learning and knowledge management: 212232. Oxford, UK: Blackwell Publishing.

Taylor, S. S., Rudolph, J. W., \& Foldy, E. G. 2007. Teaching reflective practice in the action science/action inquiry tradition: Key stages, concepts and practices. Handbook of action research, 2nd ed.: 656-668.

Thatcher, S. M. B., Jehn, K. A., \& Zanutto, E. 2003. Cracks in diversity research: The effects of diversity faultlines on conflict and performance. Group Decision and Negotiation, 12(3): 217-241.

Thomas, D. A. 1989. Mentoring and irrationality: The role of racial taboos. Human Resource Management, 28(2): 279-290.

Thomas, D. A., \& Ely, R. J. 1996. Making differences matter: A new paradigm for managing diversity. Harvard Business Review, 74(September-October): 79-90.

Torbert, W. R. 1987. Managing the corporate dream. Homewood, IL: Dow Jones-Irwin.

Torbert, W. R, \& Associates. 2004. Action inquiry: The secret of timely and transforming leadership. San Francisco: BerrettKoehler Publishers.

van Knippenberg, D., De Dreu, C. K. W., \& Homan, A. C. 2004. Work group diversity and group performance: An integrative model and research agenda. Journal of Applied Psychology, 89(6): 1008-1022.

Von Glinow, M. A., Shapiro, D. L., \& Brett, J. M. 2004. Can we talk, and should we? Managing emotional conflict in multicultural teams. Academy of Management Review, 29(4): 578-592.

Watson, W., Kumar, K., \& Michaelson, L. 1993. Cultural diversity's impact on interaction process and performance. Academy of Management Journal, 36(3): 590-602.

Webber, S. S., \& Donahue, L. M. 2001. Impact of highly and less job-related diversity on work group cohesion and performance: A meta-analysis. Journal of Management, 27: 141162.

Williams, K. Y., \& O’Reilly, C. A., III. 1998. Demography and diversity in organizations: A review of 40 years of research. Research in Organizational Behavior, 20: 77-140.

Wolsko, C., Park, B., Judd, C. M., \& Wittenbrink, B. 2000. Framing interethnic ideology: Effects of multicultural and colorblind perspectives on judgments of groups and individuals. Journal of Personality and Social Psychology, 78(4): 635-664.

Yoshino, K. 2006. Covering: The hidden assault on our civil rights. New York: Random House.

Zellmer-Bruhn, M., \& Gibson, C. 2006. Multinational organization context: Implications for team learning and performance. Academy of Management Journal, 49(3): 501-518.

Erica Gabrielle Foldy is assistant professor of public and nonprofit management at the Wagner School of Public Service, New York University. Her research explores what enables and inhibits working and learning together across potential divides such as race and gender. In 2007/2008, she was a Visiting Scholar at the Russell Sage Foundation.

Peter Rivard (privard@suffolk.edu) is assistant professor of healthcare administration at Suffolk University's Sawyer Business School, Boston, MA. He studies how middle managers promote group and organizational learning. Rivard's recent research has explored this work in the domain of patient safety improvement in healthcare organizations. His current teaching and research follow a 17-year career in healthcare management.

Tamara Buckley (tamara.buckley@hunter.cuny.edu) is a New York State-licensed psychologist and associate professor in the Department of Educational Foundations and Counseling Programs at Hunter College, City University of New York. A recent Visiting Scholar at the Russell Sage Foundation (2007/2008), Dr. Buckley's current research focuses on racial identity and multicultural competency. 
Copyright of Academy of Management Learning \& Education is the property of Academy of Management and its content may not be copied or emailed to multiple sites or posted to a listserv without the copyright holder's express written permission. However, users may print, download, or email articles for individual use. 